\title{
A recuperación da memoria histórica: Guerra Civil, represión e exilio en Ediciós do Castro*
}

\author{
Recovering Historical Memory: Civil War, Repression and \\ Exile in Ediciós do Castro
}

\author{
María Rosario Portela Yáñez \\ Consello da Cultura Galega \\ Arquivo da Emigración Galega \\ rosario.portela.yanez@udc.es
}

[recibido 15/10/2014, aceptado 06/02/2015]

\begin{abstract}
RESUMO
A liña editorial que define Ediciós do Castro é a da recuperación da memoria histórica de Galiza, sen distinción de xéneros, autores ou formato. En realidade, máis que unha liña editorial, podemos falar dun fío condutor que se concretaría no estudo da historia da Guerra Civil, a represión e o exilio; un fío que vertebrou dun modo ou outro todas as coleccións de Ediciós do Castro. Neste traballo analízanse dúas coleccións: "Documentos" e a "Biblioteca del Exilio", coa intención de poñer en valor o traballo feito dende a editorial, xa desaparecida, e homenaxear a figura do seu creador, Isaac Díaz Pardo.
\end{abstract}

Palabras ChaVe: Memoria histórica, edición, represión, exilio, Ediciós do Castro, Isaac Díaz Pardo.

\section{RESUMEN}

La línea editorial que define Ediciós do Castro es la de la recuperación de la memoria histórica de Galiza, sin distinción de géneros, autores o formato. En realidad, más que una línea editorial, podemos hablar de un hilo conductor que se concretaría en el estudio de la historia de la Guerra Civil, la represión y el exilio; un hilo que vertebró de un modo u otro todas las colecciones de Ediciós do Castro. En este trabajo se analizan dos colecciones: "Documentos" y la "Biblioteca del Exilio", con la intención de poner en valor el trabajo hecho desde la editorial, ya desaparecida, y homenajear la figura de su creador, Isaac Díaz Pardo.

PALABRAS Clave: Memoria histórica, edición, represión, exilio, Ediciós do Castro, Isaac Díaz Pardo.

\begin{abstract}
Recovering Galician historical memory defines the aim of the editorial Ediciós do Castro, without discriminating as regards gender, authors or format. In fact, instead of an editorial line, we could say this is a thread which runs through all collections of Ediciós do Castro, especially when studying the history of the Civil War, repression and exile. This work analyses two collections: "Documents" and "Library of the exile", and aims to highlight the value of the editorial's work, despite its disappearance and to make tribute to its creator, Isaac Díaz Pardo.
\end{abstract}

KEY WORDS: Historical memory, edition, repression, exile, Ediciós do Castro, Isaac Díaz Pardo.

Portela YÁÑEz, Ma R. (2015): “A recuperación da memoria histórica: Guerra Civil, represión e exilio en Ediciós do Castro”, Madrygal (Madr), 18, Núm. Especial: 509-516.

SUMARIO: 1. Introdución. 2. "Documentos". 3. A "Biblioteca del exilio". 4. Coda: A "Biblioteca do 36" e o final da editorial. 5. Referencias bibliográficas.

\footnotetext{
* Este traballo está realizado ao abeiro de dous proxectos complementarios: "La producción editorial en Galicia durante la etapa franquista (1939-1975)" (FFI2010-16924) e "Produción e mercado editorial en Galiza durante a etapa franquista: a súa incidencia na industria editorial actual" (10SEC104017PR).
} 


\section{INTRODUCIÓN}

Escribía hai algúns anos Ramón Villares, a propósito da biografía de Isaac Díaz Pardo:

E, como nervio que lle dá sentido a tal biografía, un elemento vertebrador: a memoria, como un fío que zurce unha vida. Se hai unha teima que defina a acción cultural e a promoción de institucións que alentou Isaac é a de concibilas como un deber de memoria, como un acto de xustiza cunha Terra e cunhas xentes. (Villares 2006: 21)

En 1963, da man de Luís Seoane e Isaac Díaz Pardo, nace Ediciós do Castro. A creación da editorial respondía á intención de estudar e divulgar a memoria histórica de Galiza, obxectivo principal do programa de actuacións do Laboratorio de Formas de Galiza, a quen se deben, xunto con outras empresas, as Ediciós do Castro: “...a carón de emprendementos para producir e reproducir obxectos industriais (...), había que promocionar e espallar o estudo da historia contemporánea de Galiza" (Fandiño 2012: 74) ${ }^{1}$. Este sería un mandato que o Laboratorio de Formas traía de América e co que foi marcando as empresas que creou.

Tal como figura na cuberta posterior do seu Catálogo, Ediciós de Castro, concibida como órgano de divulgación do Laboratorio de Formas, comezou a súa andaina no 1963 coa publicación de dous álbums de Luís Seoane ${ }^{2}$, quen publicou con este selo os primeiros orixinais posibles: El Toro Júbilo e $O \mathrm{Meco}$, colección de gravados que xa tiñan un significado para quen puidera entendelos.

Co tempo, a editorial comezou a crear diversas coleccións, como as que correspondían a outras iniciativas do Laboratorio como o
Seminario de Sargadelos, o Laboratorio Xeolóxico de Laxe, o Seminario de Estudos Galegos e as dedicadas á creación literaria. Mais se hai unha liña editorial que defina a Ediciós do Castro, esta sería a da recuperación da memoria histórica de Galiza, sen distinción de xéneros, autores ou formato. En realidade, máis ca unha liña editorial, podemos falar dun fío condutor, ou como dicía Villares, dun elemento vertebrador. Este fío condutor aglutina a meirande parte dos 1350 títulos que chegou a publicar a editorial nos seus 45 anos de vida (1963-2008), mais hai dúas coleccións dedicadas por enteiro á temática que dá título á nosa comunicación: "Documentos" e a "Biblioteca del Exilio". Como sería de todo xeito imposible analizar un corpo documental tan extenso como o catálogo desta editorial, imos centrarnos nestas dúas coleccións, e máis concretamente, na súa historia.

\section{2. "DOCUMENTOS"}

A principios dos anos 80, concibida por Díaz Pardo, iníciase unha nova colección, a máis emblemática dentro das que conforman a editorial: Documentos pra a Historia Contemporánea de Galiza. Xa no ${ }^{\circ} 1$, La sociedad incompleta. El drama de la capitalidad en Galicia, de Baldomero Cores (1981), aparece toda unha declaración de intencións do que se pretendía facer con esta colección:

Baixo este titular Ediciós do Castro inicia unha colección coa intención de contribuír á divulgación de testemuñas que podan axudar a facer unha aproximación á historia contemporánea de Galiza. As circunstancias que atraparon á nosa terra no ano 1936 fan difícil esta tarefa. Pero sería mala cousa que en función de razóns

\footnotetext{
${ }^{1}$ Para coñecer mellor a creación do Laboratorio de Formas de Galiza, véxase Díaz Pardo (1987), un dos catro capítulos que conforman o folleto Tradición e futuro, que se reproduce no ${ }^{\circ}$ XXIV dos Cadernos Ramón Piñeiro (Fandiño 2012: 73-85). Da creación e historia desta entidade ocúpase tamén Xosé Díaz Arias de Castro (2006: 257-268 e 2008: 41-66).

2 "Os Seoane permanecen no Castro, na casa de Díaz Pardo todo o verán de 1963, onde se lle prepara a Luís un estudio para traballar. Esta estancia co contacto diario entre os dous deu lugar á programación de varios proxectos. Prográmase o Laboratorio de Formas (...) No Laboratorio de Formas entraron varios proxectos. Un deles foi unha vella idea de Luís Seoane: un Museo de Arte Galega a partir de Castelao. Outro era a recuperación do espírito industrial e configurativo que se establecera había dous séculos en Sargadelos. Un terceiro a creación dunha editorial (á que logo se sumou unha industria gráfica)" (Díaz 2004: 65).
} 
alleas á historia, aínda que valiosas dende algún punto de convivencia, o noso acontecer recente fose silenciado, borrado ou desfigurado; porque temos a seguranza de que o futuro vai ficar lastrado das mesmas chatas que sufra a memoria. (...) Ediciós do Castro vai tratar de recoller as testemuñas que fican e animar a que se fagan investigacións sobre a historia social, económica e política dos momentos máis críticos do século, recabando toda a testemuña posible. Sabemos que o material non vai ser moito (...) Mais serán unhas cantas testemuñas o único posible que podemos deixar, para servir ao futuro, reconstruíndo no que se poda a idea do noso pasado inmediato. (1981: lapela interna)

Este escrito de Díaz Pardo, que aparece sen asinar, e que se reproduce nas lapelas dos libros desta colección ${ }^{3}$, constitúe un documento dun grande valor sobre o que non se ten reparado na súa xusta medida.

En 1993, coincidindo co 30 aniversario da creación da editorial, e co gallo da saída do prelo do $\mathrm{n}^{\mathrm{o}} 100$ da colección -Retallos para un tempo distinto, de Herminio Barreiro-, preparouse unha exposición conmemorativa cos 100 títulos editados ata ese momento. Unha exposición que se presentou en Vigo da man de Isaac Díaz Pardo, Francisco Fernández del Riego e Luís Lamela, e que percorreu nese ano diferentes cidades de Galiza para celebrar o éxito e a continuidade dunha colección que o profesor Alonso Montero definiu como "a meniña dos ollos de Díaz Pardo" (2006: 383).

É nesta época cando Díaz Pardo modifica o primeiro parágrafo do texto das lapelas e engade:

Cando temos pasado os 100 números da serie DOCUMENTOS debemos recoñecer que non se cumpriu o noso temor de acadar moi poucos testemuños e estudos pra recuperar a nosa historia recente. Mais, a medida que se adquiren coñecementos, vese que son moitos máis os que fallan, e que a unha boa parte deles non se chegará xamais por se ter perdida toda referencia, o que resulta verdadeiramente dramático. (1993: lapela interna)

E realmente así foi, pois en escasos 12 anos publicáronse estes 100 títulos. Agora, este texto programático remataba así:

Ao pouco tempo de iniciar esta serie/Documentos, viuse que a nosa historia non fica illada dos aconteceres do resto do mundo e ás veces foi xente non galega lonxe de nós a que condicionou a nosa sorte. Así, rematamos por lle chamar só "Documentos", vindo a coincidir como en xeral, por brevidade, se lle chama. (1993: lapela interna)
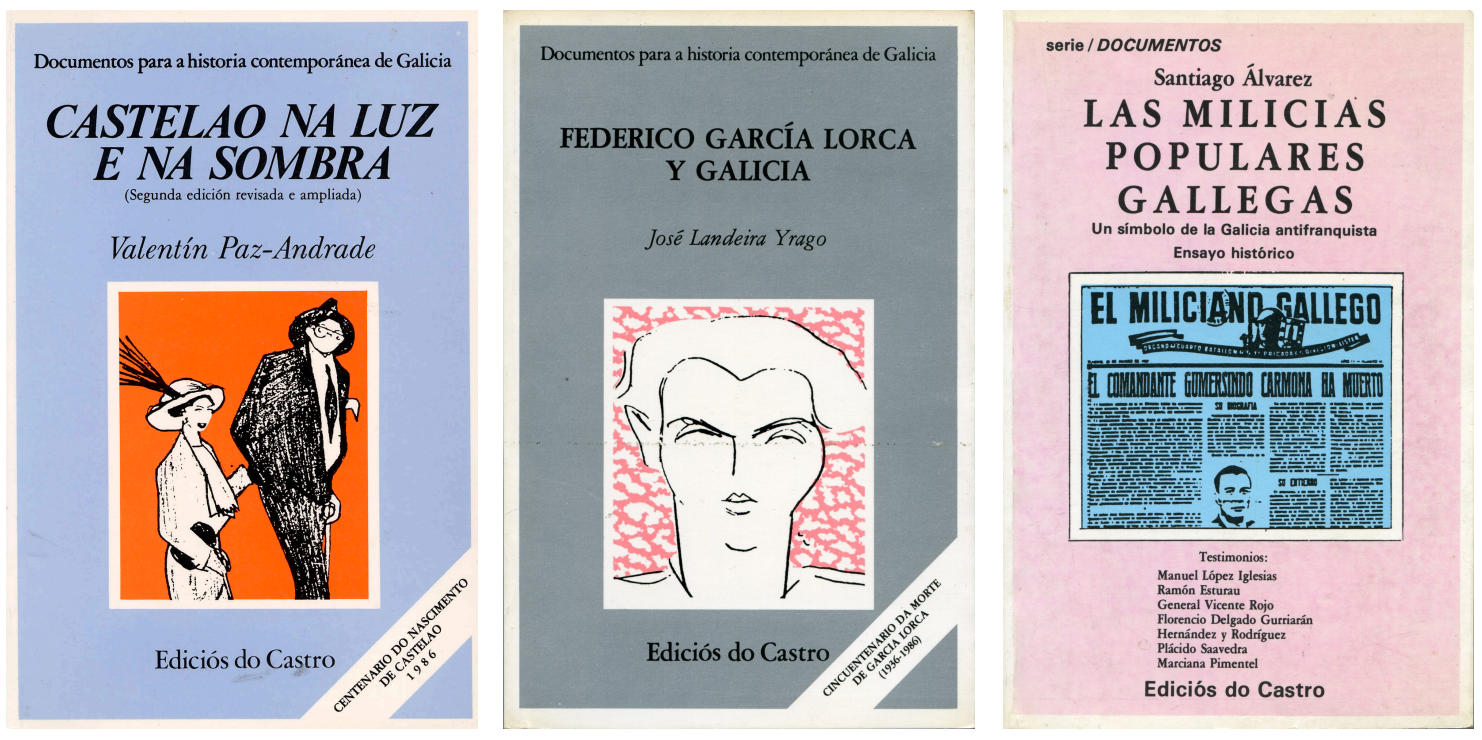

${ }^{3}$ Para a importancia dos paratextos, véxase Sanmartín Rei (2002). 

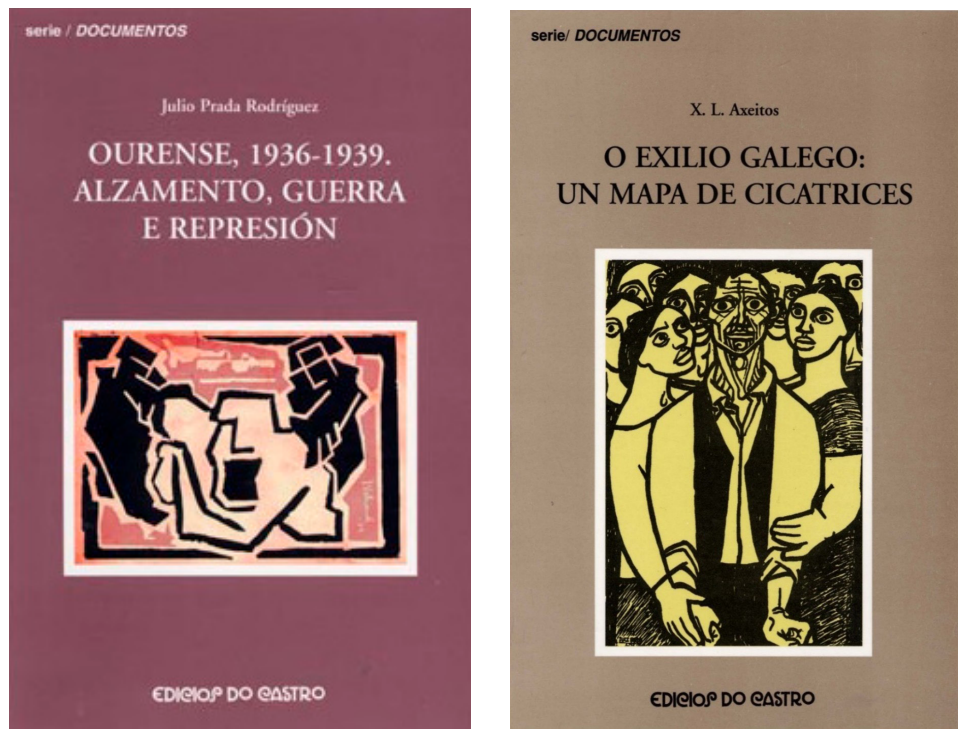

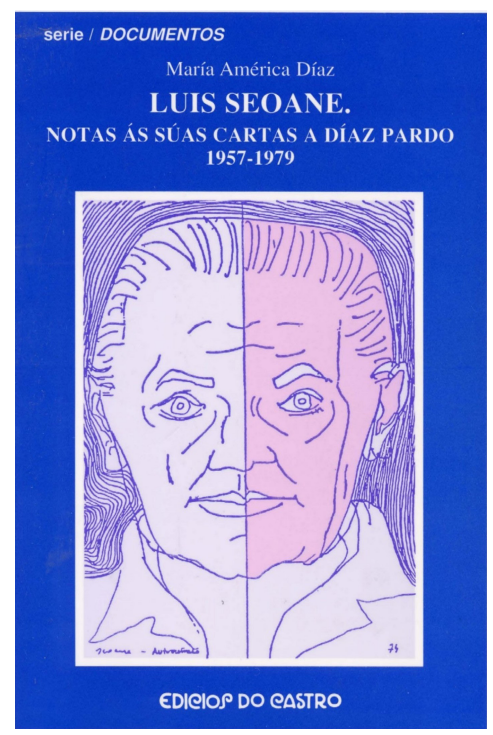

Na colección hai títulos realmente significativos sobre a represión franquista: as dúas edicións de Carlos Fernández Santander de El alzamiento de 1936 en Galicia, Cuatro años a bordo de una isla de Evaristo Mosquera, Os que non morreron e A crueldade inútil de Xerardo Díaz, as Memorias de Santiago Álvarez, Emilio González López, Francisco Fernández del Riego ou Lois Tobío.

Os libros de Luís Lamela, un dos pioneiros da historia da represión en Galiza: Pepe Miñones, un crimen en la leyenda, Inmolados gallegos, Crónica de una represión en la Costa da morte, Estampas de injusticia. La guerra civil del 36 en A Coruña y los documentos originados en la represión, A Coruña, 1936: memoria convulsa de una represión, 1936. La "cruzada" en Compostela. Pero tamén hai que citar Ourense, 1936-1939. Alzamento, guerra e represión de Xulio Prada, o Censo de guerrilleiros antifranquistas na Galiza de Francisco $\mathrm{X}$. Redondo Abal, Vixiancia e represión na Galiza da guerra civil. O informe Brandariz de Emilio Grandío, La represión franquista en la provincia de Lugo de María Jesús Souto
Blanco, $O$ ruido da morte. A represión franquista en Ponteareas de Angel Rodríguez Gallardo, a Historia do PCE en Galicia de Víctor Manuel Santidrián Arias ou Os cadernos dun prisioneiro de guerra de Angel Johán, entre tantos outros. Os máis de 200 títulos desta colección constitúen a colección galega máis importante de memorias, testemuñas, biografías e estudos sobre a Segunda República, a Guerra Civil, o exilio e o franquismo.

Esta emblemática colección acadou un grande e xeral recoñecemento da crítica e dos lectores, que fixeron dalgúns dos seus títulos un éxito de ventas ${ }^{4}$, comezando polo Castelao na luz e na sombra de Valentín Paz-Andrade (3 edicións), El alzamiento de 1936 en Galicia de Carlos Fernández Santander (4 edicións), Guerrilleiros de Neira Vilas (3 edicións), Foucellas de Luís Lamela (6 edicións) ou El último pirata del Mediterráneo de M. Domínguez Benavides (4 edicións), e con moitos dos seus títulos reeditados cando menos unha segunda vez; e isto malia tratarse da colección que tiña a tiraxe máis elevada de entre todas as que conformaban o fondo editorial.

\footnotetext{
${ }^{4}$ Para coñecer con máis detalle os antecedentes e o nacemento deste novo proxecto editorial, véxase Aznar Soler (2007: 42-45).
} 
O último título publicado da colección "Documentos" é o que fai o no 210: Sementeira e memoria. Represalia e desagravio dun médico lucense republicano, de José Luís Díaz Gómez, que saíu do prelo en 2009, e non puido ser impreso nas históricas Gráficas do Castro/Moret, pois nese momento Díaz Pardo xa fora apartado da dirección das empresas que el creara e a imprenta do Castro, desmantelada. Así que o editor, que neste libro se vai declarar na cuberta posterior ${ }^{5}$ un "militante da memoria", decide romper co silencio imposto polos "que se quedaron con todo" e sufraga a impresión deste título nas Gráficas Minerva de Santiago, aínda que baixo o selo de Ediciós do Castro.

\section{A "BIBLIOTECA DEL EXILIO"}

Unha nova colección aparece no ano 2000, un proxecto "ilusionante" co que Díaz Pardo se compromete coa forza dun mozo malia estar achegándose xa aos oitenta anos: a "Biblioteca del Exilio". Esta nova colección simboliza o espírito que anima ás empresas: loitar contra o silencio e o esquecemento que rodearon os exiliados republicanos de 1939, e recuperar así un patrimonio intelectual que complete a historia da literatura e da cultura do século XX.

A "Biblioteca del Exilio" é unha singular colección que ten a pretensión de publicar 100 obras escritas por autores do noso exilio republicano. De cada libro é responsable un investigador cualificado que prepara a edición da obra e o estudo introdutorio. Este proxecto viuse enriquecido con dúas novas series: "Anexos", dedicada á edición de textos memorialísticos e de ensaio, e a "Menor", aberta a todos os xéneros literarios, pero dun reducido número de páxinas.

Este proxecto editorial naceu o 18 de decembro de 1999, na clausura en Collioure do Congreso plural "60 Años Después", o último dun grupo de congresos coordinados polo Grupo de Estudios del Exilio Literario (GEXEL) da Universidade Autónoma de Barcelona dirixido por Manuel Aznar Soler. Unha serie de coloquios que se celebraron ese ano en 12 comunidades autónomas (o primeiro en Santiago de Compostela, baixo o patrocinio de Díaz Pardo) dedicados á historia, a literatura e a cultura do noso exilio republicano. A Biblioteca del Exilio, cun comité editorial constituído por Manuel Aznar Soler, Isaac Díaz Pardo, José Esteban, Abelardo Linares e Charo Portela Yáñez, conta cun Consello Asesor do que forman parte Xosé Luís Axeitos, Xesús Alonso Montero, Carlos Blanco Aguinaga, Francisco Caudet, Rafael Conte, Nigel Dennis, Eulalio Ferrer Rodríguez, José Carlos Mainer e James Valender.

Os diferentes títulos publícanse conxuntamente por Ediciós do Castro e Editorial Renacimiento de Sevilla, nun proxecto no que Ediciós do Castro pretende, por vez primeira, unha colaboración continuada con outra editorial de ámbito nacional. Tras a reunión fundacional que se celebrou o 19 de febreiro de 2000 en Madrid (como a meirande parte das que se realizaron posteriormente), nese mesmo ano apareceu o número 1 da colección: Artículos y ensayos de Juan Rejano, en edición de Manuel Aznar Soler (Renacimiento, 2000), seguido de Fábula y vida, de Juan Chabás en edición de Javier Pérez Bazo (Ediciós do Castro, 2000) e o primeiro tomo da Poesía Completa de Lorenzo Varela en edición de Xosé Luís Axeitos (Ediciós do Castro, 2000). E así ata chegar aos case 50 títulos con que conta na actualidade ${ }^{7}$.

Unha simple ollada á nómina de autores que aparecen aquí publicados pode dar fe da importancia desta colección: Eugenio Fernández Granell, María Teresa Léon, Esteban Salazar Chapela, Carmen de Zulueta, José

\footnotetext{
${ }^{5}$ De novo, cómpre resaltar a importancia dos "paratextos" para a historia da edición en Galiza.

${ }^{6}$ Para coñecer con máis detalle os antecedentes e o nacemento deste novo proxecto editorial, véxase Aznar Soler (2007: 42-45).

${ }^{7}$ Para unha información detallada de todas e cada unha destas publicacións véxase o apartado específico da "Biblioteca del Exilio" no Catálogo de Editorial Renacimiento: http://www.editorialrenacimiento.com/.
} 

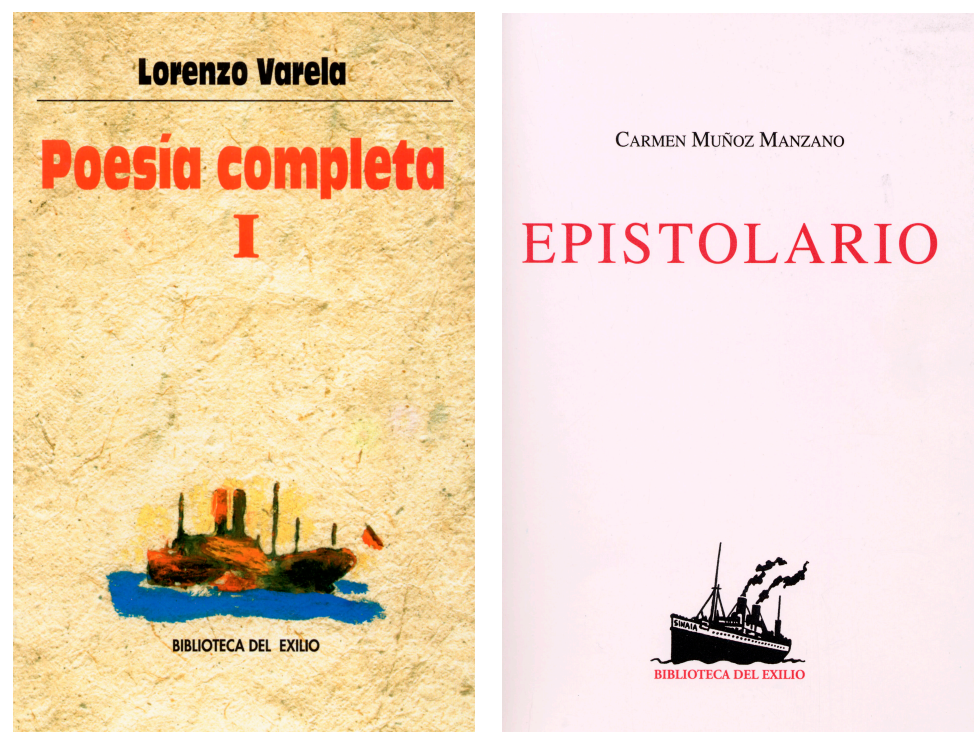

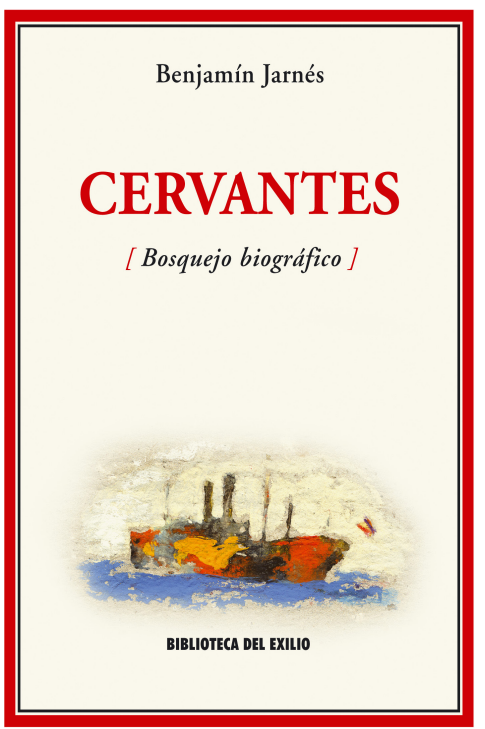

Herrera Petere, Luisa Carnés, Luis Cernuda, José Ricardo Morales, Max Aub, José Ferrater Mora, Vicente Llorens, Adolfo Sánchez Vázquez, Arturo Serrano Plaja ou Lino Novás Calvo, entre tantos outros. Este proxecto pretende tamén dar a coñecer a autores dos que pouco sabemos como Luis Quintanilla, o galego Álvaro Fernández Suárez ou Roberto Ruiz (a quen a Biblioteca del Exilio lle publica en 2005, Juicio y condena del hombre nuevo, a súa primeira novela en España!). Un labor, en fin, que pretende rescatar dun inxusto esquecemento o labor do exilio republicano.

En novembro de 2006 presentouse en Galicia a "Biblioteca del Exilio", coa presenza de todos os membros do Comité Editorial, e dende Ediciós do Castro, aproveitouse para acompañar esta presentación cunha exposición bibliográfica sobre a Guerra Civil e o exilio $^{8}$ que incluía todos os títulos que sobre este tema publicara Ediciós do Castro; mais tamén moitos dos antecedentes que tivo a "Biblioteca del Exilio", como a colección "Memoria
Rota" de Anthropos, os libros de GEXEL, a colección "Clavo Ardiendo" de Renacimiento, os libros de Ruedo Ibérico ${ }^{9}$ e, quizais o máis significativo, unha ampla mostra do que publicou durante moitos anos en diferentes lugares do mundo a "España peregrina", con presenza destacada de libros e revistas publicados en México e, sobre todo, en Arxentina. No 2008 presentouse a colección en Madrid, na Casa de América, coa presenza do entón Ministro de Cultura, o galego César Antonio Molina.

Hoxe, a "Biblioteca del Exilio" continúa publicando a un ritmo de 5 ou 6 títulos anuais grazas ao tesón do editor Abelardo Linares, de Editorial Renacimiento, pois Ediciós do Castro sacou do prelo o último libro desta colección en $2008^{10}$.

Aínda que Ediciós do Castro xa non tiña capacidade de produción logo desta data e as reunións anuais do Comité Editorial tiñan lugar habitualmente en Madrid, a Biblioteca del Exilio celebrou dúas das súas reunións nos

${ }^{8}$ Para máis información sobre esta exposición, véxase Portela Yáñez (2006: 11-15).

${ }^{9}$ O profesor Alonso Montero (2012: 317-322) ofrece unha análise pormenorizada da relación de Díaz Pardo coa editorial Ruedo Ibérico no Dossier que lle dedicou a Isaac a revista valenciana Laberintos. Revista de estudios sobre los exilios culturales españoles no ano 2012.

${ }^{10}$ Anexo 11 da colección: Las hogueras del Perthús. Diario de la evacuación de Cataluña, de Álvaro de Orriols, en edición de Manuel Aznar Soler (Biblioteca del Exilio). 
anos 2010 e 2011 no estudio de Díaz Pardo, no Castro de Samoedo. A de novembro de 2011 foi, fundamentalmente, un acto de homenaxe e despedida a Isaac, quen falecería pouco despois.

\section{CODA: A "BIBLIOTECA DO 36" E O FINAL DA EDITORIAL}

Xa no ano 2007, e continuando coa liña editorial, iniciouse a publicación da "Biblioteca do 36", baixo a dirección de Xesús Alonso Montero -habitual colaborador de Ediciós do Castro-, coa obra Versos de preso e outras rimas (da Guerra Civil ó 1975), de Evaristo de Sela (en edición de Stella Maris González Balbuena), unha obra e un autor que simbolizan a pretensión desta nova serie: dar a coñecer obras literarias -éditas ou inéditas- dos escritores e escritoras de Galicia que, neses corenta anos, foron obxecto dalgún tipo de represión. A colección continuou con $A$ volta da perdida: obra inédita incautada polos militares en 1936, de Urbano R. Moledo (en edición de Rexina R. Vega), que saíu do prelo no mesmo ano.

Malia os atrancos que a editorial estaba a ter nestes anos, seguía coa teima de recuperar a memoria histórica de Galiza. Desgraciadamente, a colección viuse truncada nos seus inicios e non puido sacar máis títulos logo do ano 2007.

En realidade, a historia da Guerra Civil, da represión e do exilio é o fío condutor de todas as coleccións de Ediciós do Castro. Así, citemos a modo de exemplo os dous volumes da revista Unión Libre" titulados "Memoria antifascista de Galicia" e "Vermellas", os Cadernos de homenaxe a José Martínez, fundador de Ruedo Ibérico, e a Lois Tobío; as biografías de Lorenzo Varela ou Arturo Cuadrado, os epistolarios de Rafael Dieste e Carmen Muñoz, as publicacións de actas de congresos como o organizado polo Consello da Cultura Galega sobre "O Exilio Galego de 1936", ou as edicións facsimilares de revistas feitas por galegos no exilio como Galicia emigrante ou Correo literario. Podemos dicir así, sen temor a equivocarnos, que "sen Isaac e sen Ediciós do Castro, a nosa memoria hoxe por hoxe estaría profundamente eivada, mortalmente ferida" (Alonso 2006) ${ }^{12}$.

E como queremos manter viva a súa loita por recuperar a nosa memoria máis recente, temos a obriga de lembrar como foron os derradeiros anos de Isaac Díaz Pardo. Non morreu dirixindo as fábricas de Sargadelos e O Castro que el creara, nin editando libros en Ediciós do Castro, nin organizando actos no Museo Carlos Maside. Nin no seu estudo do Instituto Galego de Información, en San Marcos, onde tiña o seu arquivo, a súa biblioteca e a súa residencia. En 2006 foi apartado da dirección das empresas do Grupo Sargadelos. En febreiro de 2007 comezou a operación de desmantelamento do Instituto Galego de Información, do que foi obrigado a saír en xaneiro do ano 2010, pouco antes de cumprir os 90 anos. Foi un acto inxusto e cruel, un golpe do que pensamos non se deu recuperado.

Esta comunicación non pretende outra cousa que contar unha parte da nosa historia, poñer en valor o traballo feito dende a editorial xa desaparecida e, ao tempo, homenaxear a figura fulcral do seu creador, Isaac Díaz Pardo.

\footnotetext{
${ }^{11}$ A propósito, Unión Libre seguiu saíndo nos anos 2009 e 2010 baixo o selo de Ediciós do Castro (serían os números 14 e 15), pero en realidade a revista estaba a ser impresa e editada polos seus creadores coa axuda da Galería Sargadelos de Lugo, pois Ediciós do Castro xa non podía editar libros nese momento.

${ }^{12}$ Palabras tomadas da laudatio que pronunciou Fran Alonso con motivo do nomeamento de Díaz Pardo como Presidente de Honra da Asociación Galega de Editores, en maio de 2006.
} 


\section{REFERENCIAS BIBLIOGRÁFICAS}

Alonso, Francisco (2006): Isaac Díaz Pardo, Presidente de Honra (dispoñíbel en: http://cabrafanadablog.blogspot.com.es/2012/01/mina-homenaxe-isaac-dous-textos-sobre.html).

Alonso Montero, Xesús (2006): "Isaac, editor da memoria”, en X. Díaz Arias de Castro e G. Escrigas (eds.), Isaac Díaz Pardo. Creación e compromiso na Galicia do século XX. A Coruña: Deputación Provincial, pp. 383-395.

(2012): "Isaac Díaz Pardo, colaborador intelectual y económico de la editorial antifranquista Ruedo Ibérico (París)", Laberintos. Revista de estudios sobre los exilios culturales españoles 14, pp. 317-322 (dispoñíbel en: http://bv.gva.es/documentos/lab14.pdf).

Aznar Soler, Manuel (2007): "La Biblioteca del Exilio: testimonio de homenaje a Isaac Díaz Pardo", en I. Díaz Pardo. Homenaxe galega. Ferrol: Asociación Cultural Fuco Buxán, pp. 37-47.

Díaz Arias de Castro, Xosé (2006): “O Laboratorio de Formas de Galicia”, en X. Díaz Arias de Castro e G. Escrigas (eds.), Isaac Díaz Pardo. Creación e compromiso na Galicia do século $X X$. A Coruña: Deputación Provincial, pp. 257-268.

(coord.) (2008): Sargadelos recuperado. O Laboratorio de Formas 40 anos despois. A Coruña: Fundación Luís Seoane.

Díaz Arias de Castro, Xosé, Luís Muñoz e Juan Rodríguez (2001): Arte, Industria, Isaac Díaz Pardo. Santiago de Compostela: Labirinto de paixóns, Colexio Oficial de Arquitectos de Galicia.

DíAz, Ma América (2004): Luís Seoane. Notas ás súas cartas a Díaz Pardo. Sada: Ediciós do Castro.

DíAz PARDo, Isaac (1981): Lapela interna (sen asinar), en B. Cores Trasmonte, El drama de la capitalidad en Galicia. Sada: Ediciós do Castro.

(1987): Tradición e futuro (folleto). Sada: Ediciós do Castro.

(1993): Lapela interna (sen asinar), en C. Fernández Santader, La Voz de Galicia. Crónica de un periódico. Sada: Ediciós do Castro.

EDICIÓs do CASTRO (web): http://www.sargadelos.com/edicionsocastro/?lg=gal ${ }^{13}$.

EDITORIAL RENACIMIENTO (web): www.editorialrenacimiento.com.

FAndiÑo, Ramón (ed.) (2012): A luminosa mirada dos ollos de Isaac. Isaac Díaz Pardo. Obra dispersa (Cadernos Ramón Piñeiro 24). Santiago de Compostela: Centro Ramón Piñeiro para a Investigación en Humanidades.

SANMARTín ReI, Goretti (2002): Lendo nas marxes. Lingua e compromiso nos paratextos. A Coruña: Espiral Maior.

Portela YÁñez, Charo (2006): "Libros da guerra civil e do exilio. Libros da memoria", en Presentación da Biblioteca del Exilio e unha exposición bibliográfica sobre a guerra civil e o exilio (folleto). Sada: Ediciós do Castro.

Villares, Ramón (2006): “Un grande contemporáneo”, en X. Díaz Arias de Castro e G. Escrigas (eds.), Isaac Díaz Pardo. Creación e compromiso na Galicia do século XX. A Coruña: Deputación Provincial, pp. 15-21.

VV. AA. (2007): Catálogo Ediciós do Castro. Sada: Ediciós do Castro.

\footnotetext{
${ }^{13} \mathrm{Na}$ web do grupo Sargadelos só aparece un arquivo pdf do Catálogo de Ediciós do Castro que corresponde ao ano 2005, polo que non inclúe ningunha das publicacións posteriores a esa data.
} 